\title{
The Association of Lung Age with Smoking Original The Association of Lung Age with Smoking Article Status in Korean Men
}

\author{
Hye Young Oh, Hong Soo Lee ${ }^{1, *}$, Sang Wha Lee ${ }^{1}$, Kyung Won Shim ${ }^{1}$, \\ Hyejin Chun', Joo Yeon Kim²
}

Department of Family Medicine, Hallym University Sacred Heart Hospital, Anyang; ${ }^{1}$ Department of Family Medicine, Ewha Womans University Medical Center; ${ }^{2}$ Department of Family Medicine, Seoul Medical Center; Seoul, Korea

Background: Lung age, calculated from sex, forced expiratory volume in one second $\left(\mathrm{FEV}_{1}\right)$, and height, was developed to illustrate premature changes to the lungs and could be used to motivate smoking cessation. However, this method has not been tested in association with smoking in Korea. The purpose of this study was to investigate the association of lung age with smoking and other factors in Korean males.

Methods: We reviewed the records of 1,100 healthy men who visited a health promotion center at Ewha Womans University Medical Center from January 2008 to June 2009. Lung age was calculated from $\mathrm{FEV}_{1}$ and normal predictive values of spirometry according to age in the Korean population. The difference between lung age and chronological age was evaluated in relation to smoking status, weight, body mass index, waist, muscle mass, fat mass, and exercise.

Results: The age difference was significantly higher in current smokers than in non-smokers $(12.47 \pm 19.90$ vs. $7.30 \pm 19.52$, $\mathrm{P}<0.001)$. Additionally, the age difference was positively correlated with life time pack-year $(\beta=0.223$; $\mathrm{P}<0.001)$ and fat mass $(\beta=0.462 ; \mathrm{P}<0.001)$. Lung age increased 1 year for 4.48 pack-year increase or for $2.16 \%$ increase in fat mass.

Conclusion: We found a significant relationship between lung age and both smoking status and fat mass in healthy Korean males. Lung age may be a useful tool for motivating cessation of cigarette smoking and management of risk factors related to obesity.

Keywords: Lung Age; Smoking; Male; Spirometry; Forced Expiratory Volume 1; Obesity

\section{INTRODUCTION}

Risks of smoking have been identified in multiple landmark studies, ${ }^{1,2)}$ and it is the most important modifiable risk factor in mortality rates. According to the Korea National Health and

Received: August 31, 2010, Accepted: December 10, 2013

${ }^{*}$ Corresponding Author: Hong Soo Lee

Tel: +82-2-2650-5165, Fax: +82-2-2650-2439

E-mail: dongyn@kornet.net

Korean Journal of Family Medicine

Copyright (C) 2014 The Korean Academy of Family Medicine

(c) This is an open-access article distributed under the terms of the Creative Commons Attribution Non-Commercial License (http://creativecommons.org/licenses/by-nc/3.0) which permits unrestricted noncommercial use, distribution, and reproduction in any medium, provided the original work is properly cited.
Nutrition Examination Survey (Ministry of Health and Welfare, 2007), 45.0\% of Korean men were smokers. Despite a continuous decrease in the prevalence of smokers since the 1980's, South Korea remains in the top 20 of smoking populations worldwide (The Tobacco Atlas 3rd edition).

A quarter of smokers are affected by chronic obstructive pulmonary disease (COPD), ${ }^{3)}$ which is diagnosed about 20 years after the onset of disease. ${ }^{4)}$ To prevent irreversible changes in the lungs, it is important to diagnose COPD early and to help smokers to quit. ${ }^{5)}$ Interventions include individual or group counseling, and pharmacological therapies. Another possible strategy for increasing cessation rates is to provide feedback on the physical effects of smoking by physiological measurements. Several studies have examined the effect of biomarkers, such as impaired lung function, carbon monoxide, atherosclerotic plaque, 
and CYP2D6 genotype lung cancer susceptibility, on smoking cessation rate, but there is a lack of evidence on the effects of biomarkers for risk assessment. $^{2)}$

To counsel the results of pulmonary function tests to patients, the concept of 'lung age' was introduced by Morris and Temple ${ }^{5)}$ in 1985. Lung age is estimated from regression equations for the forced expiratory volume in one second $\left(\mathrm{FEV}_{1}\right)$ in healthy never-smokers, ${ }^{5-7)}$ (Table 1) and constitutes the age at which the $\mathrm{FEV}_{1}$ measured in an individual equals the predicted value of $\mathrm{FEV}_{1}$, taking into account age, height, sex, and ethnicity. ${ }^{8)}$ This concept has received international attention, and has been used to warn individuals against the pulmonary impairment caused by smoking. ${ }^{6)}$ In the randomized controlled trial by Parkes et al., ${ }^{8)}$ informing smokers of individual lung age significantly improved the likelihood of smoking cessation, when compared to informing $\mathrm{FEV}_{1}$, although this effect was unrelated with the severity of decreased $\mathrm{FEV}_{1}$. A qualitative study among COPD patients examined the results of providing patients with their lung age at the point of diagnosis in hopes of promoting behavioral change. ${ }^{9)}$ The Japanese Respiratory Society recommends the use of lung age in the risk management of COPD. ${ }^{6}$ Screening of lung disease with lung age was useful, ${ }^{10)}$ and various indicators of obesity may also be related with lung age. ${ }^{6}$

Interpretation of spirometry results in terms of 'lung age' had a significant effect in a meta-analysis. ${ }^{2)}$ Lung age is frequently used to promote smoking cessation in other nations, but has not thoroughly been examined in Korea. Thus, we investigated the association between lung age and smoking status in Korean men, using lung age calculated from the predicted $\mathrm{FEV}_{1}$ of Koreans. ${ }^{11)}$ The relationships were also evaluated between lung age and other factors known to affect lung function.

\section{METHODS}

\section{Study Population}

This was a cross-sectional retrospective review of the period between January 2008 and June 2009 (The study was conducted after June 2009). The target population was males aged 20 years or older who visited the health promotion center at Ewha Womans University Hospital. Subjects were eligible if they received a pulmonary function test, chest radiograph, body composition measurements, and anthropometric measurements including height, weight, and waist circumference. A self-administered questionnaire was distributed, and completed questionnaires were returned during a clinical visit. We obtained baseline data regarding age, smoking history in pack years (average daily number of cigarettes smoked divided by 20 and multiplied by the number of years of smoking), medical history, medication, exercise frequency and duration, and comorbidity including chronic bronchitis or emphysema, asthma, pulmonary fibrosis, or other lung disease. Subjects were also interviewed to determine the presence of pulmonary diseases or acute respiratory symptoms. We excluded those who were taking respiratory medications, or those with a history of respiratory disease, cardiovascular disease such as angina or myocardial infarction, neck or thoracic operations, congenital anomaly, malignancy, or neuromuscular disease. None of the men included in this study had abnormal chest radiograph. The study was approved by the institutional review board of Ewha Womans University Hospital (IRB ECT-232-1-32).

\section{Pulmonary Function Tests}

Patients underwent standard spirometry (Vmax series 2130; Sensor Medics, Yorba Linda, CA, USA) according to the recommendations presented in the Guidelines of the American Thoracic Society. This was repeated at least three times, and

Table 1. Equations to predict lung age in Korean males

\begin{tabular}{ll}
\hline & \multicolumn{1}{c}{ Korean lung age equations } \\
\hline Male & Lung age $=\left(2.115 \times\right.$ height $\left.^{*}\right)-\left(46.052 \times \mathrm{FEV}_{1}^{\dagger}\right)-138.409$ \\
Female & Lung age $=\left(2.166 \times\right.$ height $\left.^{*}\right)-\left(60.475 \times \mathrm{FEV}_{1}^{\dagger}\right)-128.104$ \\
Age difference & Age difference $=$ lung age - chronologic age \\
\hline
\end{tabular}

Derived from normal predictive values of spirometry in Korean population, 2007. From Choi JK, et al. Tuberc Respir Dis 2005;58:230-42. ${ }^{11)}$ *Height (cm). ${ }^{\dagger}$ Forced expiratory volume 1 second (L). 
the highest reading was used for analysis. The machines were calibrated every morning during the study period with the use of a standard syringe. Values were corrected for body temperature, pressure, and saturation with water vapor.

\section{Equations to Predict Lung Age in Korean Males}

The population from which the subjects are drawn should be similar with respect to age, height, sex, and ethnic composition to the population from which the prediction values were derived. ${ }^{12)}$ In this manner, equations to predict lung age was derived from "normal predictive values of spirometry in the Korean population" published in 2005. Among 3 predictive equations of spirometry in men, the most predictive equation, including age and height ${ }^{5-7)}$ like other lung age studies, was selected (Table 1).

\section{Anthropometry \& Body Composition}

With the subjects wearing light indoor clothes and no shoes after fasting for more than 8 hours, weight was measured (in $\mathrm{kg}$ ) on digital weight scales which measured to the nearest $100 \mathrm{~g}$. Height was measured (in $\mathrm{cm}$ ) by stadiometer to the nearest 0.1 $\mathrm{cm}$ while participants stood, wearing no shoes, on a hard surface. Waist circumference was measured (in $\mathrm{cm}$ ) horizontally through the narrowest part of the torso, between the lowest rib and the iliac crest. Measurements were averaged between measurements separately obtained by two examiners. Total body fat, total muscle mass, percentage body fat, and percentage body muscle were measured with a bioelectrical impedance analysis device (Inbody 3.0; Biospace, Seoul, Korea).

\section{Smoking Status}

Current cigarette smokers were defined as participants who currently smoke cigarettes daily and who had smoked $\geq 5$ packs of cigarettes before the date of spirometer. Ex-smokers were defined as participants who do not currently smoke cigarettes and who had smoked $\geq 5$ packs of cigarettes before the date of spirometer. Non-smokers were defined as participants who had smoked $<5$ packs of cigarettes during their lifetime or participants who had not smoked at all in the past. ${ }^{13)}$

\section{Statistical Analysis}

We used analysis of variance with a Tukey post hoc analysis

Table 2. Baseline characteristics by smoking status $(n=1,100)$

\begin{tabular}{lcccc}
\hline \multicolumn{1}{c}{ Variables } & Non-smoker & Ex-smoker & Current smoker & P-value* \\
\hline Age (y) & $43.47 \pm 7.64$ & $46.65 \pm 7.44$ & $42.95 \pm 6.49$ & $<0.001$ \\
FEV $_{1}(\mathrm{~L})$ & $3.75 \pm 0.56$ & $3.64 \pm 0.51$ & $3.69 \pm 0.53$ & $<0.001$ \\
$\mathrm{FEV}_{1}(\%)$ & $106.0 \pm 12.2$ & $104.9 \pm 11.0$ & $102.8 \pm 12.3$ & $<0.001$ \\
Pack-year ${ }^{\dagger}$ & 0 & $12.5(7.5,20)$ & $15(10,20)$ & $<0.001^{\ddagger}$ \\
Exercise (h/wk) & $2(0,3.3)$ & $3(1,5)$ & $1.5(0,4)$ & $<0.001^{\ddagger}$ \\
Height (cm) & $171.15 \pm 5.75$ & $172.03 \pm 5.18$ & $171.93 \pm 5.77$ & 0.07 \\
Weight (kg) ${ }^{\dagger}$ & $71.6(65.7,79.1)$ & $74.3(68.1,81.1)$ & $73.25(66.6,79.8)$ & $0.002^{\ddagger}$ \\
BMI (kg/m $\left.{ }^{2}\right)$ & $24.73 \pm 2.69$ & $25.23 \pm 2.81$ & $24.89 \pm 2.95$ & 0.1 \\
Waist (cm) ${ }^{\dagger}$ & $84.0(79.5,89.0)$ & $86.0(81.6,90.4)$ & $85.0(81.0,89.9)$ & $0.01^{\ddagger}$ \\
Muscle mass (\%) & $72.32 \pm 4.79$ & $71.87 \pm 5.05$ & $72.20 \pm 4.96$ & 0.53 \\
Fat mass (\%) & $23.51 \pm 5.04$ & $23.98 \pm 5.29$ & $23.76 \pm 5.15$ & 0.52 \\
Total & $412(37.5)$ & $228(20.7)$ & $460(41.8)$ & \\
\hline
\end{tabular}

Values are presented as mean \pm SD, median (interquartile range), or number (\%).

$\mathrm{FEV}_{1}$ (\%): forced expiratory volume 1 second (calculated as observed $\mathrm{FEV}_{1}$ in liters divided by predicted $\mathrm{FEV}_{1}$ in liters multiplies 100), BMI: body mass index (calculated as weight in kilograms divided by height in meters squared).

*From analysis of variance test. ${ }^{\dagger}$ Shows median value and interquartile range. ${ }^{\ddagger}$ From Kruskal-Wallis test comparing a difference among 3 study groups. 
to analyze differences between smoking groups for normally distributed variables. The Kruskal-Wallis test was used for other types of variables. The dependent variable was age difference (lung age - chronologic age) and univariate linear regression analysis was used to test the effects of independent variables on age difference. Variables with a P-value $\leq 0.10$ in the univariate linear regression analysis or variables known to affect lung age were considered as candidates in the final multivariate model. Stepwise multiple linear regression analysis was used to select variables to be maintained in the final model. A P-value of less than 0.05 was considered statistically significant. Statistical analyses were performed using the PASW SPSS ver. 18.0 (SPSS Inc., Chicago, IL, USA).

\section{RESULTS}

\section{Baseline Characteristics of the Patients}

In total, 1,100 adult subjects were enrolled in the study. Baseline characteristics by smoking status are shown in Table 2. Of the subjects, $41.8 \%$ were current smokers, $20.7 \%$ were exsmokers, and $37.5 \%$ were never smokers. Lifetime pack year was higher for current smokers than for ex-smokers (15 vs. 12.5, $\mathrm{P}<$ 0.001). $\mathrm{FEV}_{1}$ of non-smokers was higher than that of ex-smokers or current smokers $(\mathrm{P}<0.001 ; 106.0 \%$ [3.75 $\pm 0.56 \mathrm{~L}], 104.9 \%$ $[3.64 \pm 0.5 \mathrm{~L}]$, and $102.8 \%$ [3.69 $\pm 0.53 \mathrm{~L}]$, respectively). The exsmoker group was older, had the longest exercise time per week, largest waist and weight, but non-smokers and current smoker groups did not show any difference in these variables. There were no differences in height, body mass index (BMI), muscle mass (\%), or fat mass (\%) among the 3 groups.

\section{Age Difference according to Smoking Status, Indices of Obesity}

We used age difference (lung age - chronological age) for comparison of lung age due to the higher chronological age in the ex-smokers group (Table 3 ). There was a trend toward increasing age difference in the order of non-smoker, ex-smoker, and current smoker $(\mathrm{P}<0.001 ; 7.30 \pm 19.52,11.01 \pm 18.23$, and $12.47 \pm$ 19.90, respectively). The age difference was significant between current smokers and non-smokers $(\mathrm{P}<0.001)$, but not between ex-smokers and non-smokers $(\mathrm{P}=0.05)$, or between ex-smokers and current smokers $(\mathrm{P}=0.08)$ in post hoc analysis (Figure 1 ).

Age difference was associated with life-time pack-year, and $(\beta=0.254 ; \mathrm{P}<0.001)$, weight $(\beta=0.17 ; \mathrm{P}=0.005)$, $\mathrm{BMI}(\beta=$ $0.477 ; \mathrm{P}=0.02)$, waist $(\beta=0.319 ; \mathrm{P}<0.001)$, and fat mass $(\beta=$ 0.512; $\mathrm{P}<0.001)$ showed a positive relationship. Additionally, muscle mass $(\beta=-0.530 ; \mathrm{P}<0.001)$ was negatively correlated

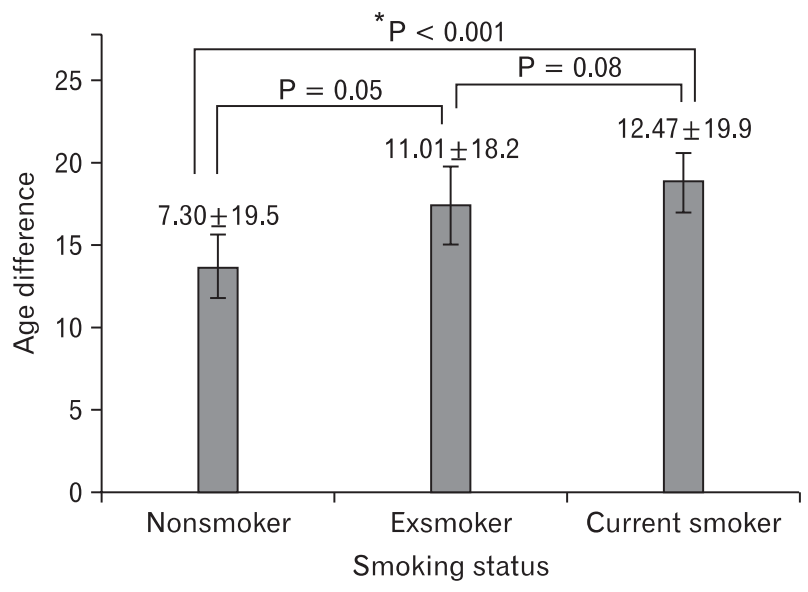

Figure 1. Comparisons of lung age difference by smoking status. Graphs show comparisons of lung age difference by smoking status. Values are presented as mean \pm SD. Bars show 95\% confidential interval. *P-values were calculated by analysis of variance. P-values in figure were calculated using Tukey test (Post Hoc).

Table 3. Comparison of lung age by smoking status

\begin{tabular}{lccr}
\hline & Chronological age & Lung age & Age difference* $^{*}$ \\
\hline Non- smoker $(\mathrm{n}=412)$ & $43.47 \pm 7.64$ & $50.77 \pm 21.22$ & $7.30 \pm 19.52$ \\
Ex-smoker $(\mathrm{n}=228)$ & $46.65 \pm 7.44$ & $57.66 \pm 21.20$ & $11.01 \pm 18.23$ \\
Current smoker $(\mathrm{n}=460)$ & $42.95 \pm 6.49$ & $55.37 \pm 21.31$ & $12.47 \pm 19.90$ \\
P-value $^{\dagger}$ & $<0.001$ & $<0.001$ & $<0.001$ \\
\hline
\end{tabular}

Values are presented as mean \pm SD.

*Age difference is lung age minus chronologic age (y). ${ }^{\dagger}$ From analysis of variance test for comparison among three groups. 
Table 4. Correlation between age difference and relevant factors identified on univariate linear regression

\begin{tabular}{lcccc}
\hline & \multicolumn{4}{c}{ Age difference } \\
\cline { 2 - 5 } & $\mathrm{r}$ & $\beta$ & SE & P-value* $^{*}$ \\
\hline Pack-year & 0.146 & 0.254 & 0.052 & $<0.001$ \\
Weight (kg) & 0.086 & 0.170 & 0.060 & 0.005 \\
Body mass index $\left(\mathrm{kg} / \mathrm{m}^{2}\right)$ & 0.069 & 0.477 & 0.208 & 0.02 \\
Waist (cm) & 0.120 & 0.319 & 0.080 & $<0.001$ \\
Muscle mass (\%) & -0.134 & -0.530 & 0.119 & $<0.001$ \\
Fat mass (\%) & 0.135 & 0.512 & 0.114 & $<0.001$ \\
Exercise (h/wk) & 0.011 & 0.083 & 0.220 & 0.700 \\
\hline
\end{tabular}

$\beta$ : regression coefficient, SE: standard error.

${ }^{*}$ Coefficients ( $\beta$ ) and P-values were calculated by univariate linear regression.

with age difference (Table 4). Among statistically significant variables in univariate regression analysis such as weight, BMI, fat mass, and muscle mass, only fat mass was included in the multivariate analysis, because the variables showed definite multicollinearity, and the correlation coefficient was greatest for fat mass. When multivariate regression analysis was performed, adjusting for age which can affect lung age, life-time pack year $(\beta=0.223 ; \mathrm{P}<0.001)$ and fat mass $(\beta=0.462 ; \mathrm{P}<0.001)$ was positively correlated with age difference, but exercise was not $(\beta=-0.008 ; \mathrm{P}=0.973)$ (Table 5). Life-time smoking of 4.48 pack-year and fat mass of $2.16 \%$ was estimated to contribute an additional gain of 1 year for lung age, respectively.

\section{DISCUSSION}

Our data show that the lung age differed significantly between current smokers and non-smokes and that lifelong total amount of smoking was positively associated with lung age, even after adjusting for other factors known to influence lung age. In our study, there was a trend toward decreased age difference in the order of current, ex-, and non-smoker. These findings are similar to those of the study by Wada, ${ }^{14)}$ who assessed the differences in the lung age among smokes, past smokers, and non-smokers in Japan, and to those of another study from Austrailia. ${ }^{7)}$ Dockery et al. ${ }^{15)}$ also reported that $\mathrm{FEV}_{1}$ decreased by $7.4 \mathrm{~mL}$ per 1 pack-year
Table 5. Regression coefficients and statistical significance of factors influencing age difference, based on multivariate linear regression adjusted for age

\begin{tabular}{lccc}
\hline & \multicolumn{3}{c}{ Age difference } \\
\cline { 2 - 4 } & $\beta$ & $\mathrm{SE}$ & P-value* $^{*}$ \\
\hline Pack-year & 0.223 & 0.053 & $<0.001$ \\
Fat mass (\%) & 0.462 & 0.113 & $<0.001$ \\
Exercise (h/wk) & -0.008 & 0.221 & 0.973 \\
\hline
\end{tabular}

Multiple correlation coefficient $\left(\mathrm{R}^{2}\right)$ was $0.037(\mathrm{P}<0.001)$. $\beta$ : regression coefficient, SE: standard error.

*Coefficients ( $\beta$ ) and P-values were calculated by entered method in multiple linear regression.

increase in lifetime pack-year for male smokers, which translated to a lung age decrease of 1 year per 3 pack-year increase. Although this is somewhat different from our result of 4.48 pack-years, the results were consistent with previous papers which described an inverse association of cigarette smoking with $\mathrm{FEV}_{1}{ }^{16-18)}$

We confirmed again the correlation of lung age with the indices of obesity known to influence lung function. ${ }^{19-23)}$ Age difference was positively related with fat mass $(\beta=0.512$; $\mathrm{P}<$ 0.001 ), waist circumference $(\beta=0.319 ; \mathrm{P}<0.001)$, and BMI $(\beta$ $=0.477 ; \mathrm{P}=0.02)$ and negatively with muscle mass $(\beta=-0.530$; $\mathrm{P}<0.001)$. In multivariate regression models substituting muscle mass or waist circumference for body fat mass, each variable demonstrated a significant association with lung age. Lung age increased 1 year for each $2.08 \%$ decrease in muscle mass $(\beta=$ $-0.481 ; \mathrm{P}<0.001)$ and $3.7 \mathrm{~cm}$ increase in waist circumference $(\beta$ $=0.270 ; \mathrm{P}=0.001$ ) (Table not shown). The negative relationship of lung age with muscle mass was pronounced after adjusting for other variables, corresponding with the correlation of $\mathrm{FEV}_{1}$ with fat free mass representative of muscle mass. ${ }^{19,23)}$ In a multivariate regression model including BMI, however, there was weaker correlation of lung age with BMI than other obesity-related indices $(\beta=0.409 ; \mathrm{P}=0.049)$. This finding is in concordance with previous publications' assertion that BMI is not an ideal measure for excess body weight as a predictor of pulmonary function compared with waist circumference or fat-free mass, because a high BMI value can result from higher muscle mass. ${ }^{19,23)}$ Therefore, our results might provide an effective tool to explain the association of lung age with body fat mass, muscle mass, and waist circumference and to presumably control obesity in non- 
smokers.

Currently, a widely used spirometric reference equation in Korea is based on the Morris equation published in 1979 for Caucasian populations. In this study, the normative predictive values of spirometry in the Korean population published in 2005 by Choi et al. ${ }^{11)}$ was used to derive predictive equation of lung age. We compared the Morris equation and the Choi equation prior to analysis. In the Morris equation, lung age was less than chronological age and was not significantly different with chronological age in current smokers. This result seems paradoxical in suggesting that smokers' lung age is younger than expected, unlike the results reported by Newbury et al. ${ }^{7)}$ In contrast, when the Choi equation was used, lung age was significantly greater than chronological age in smokers $(\mathrm{P}<0.001)$. The Choi equation was derived from a younger Korean population than our study population, and the index study barely included any elderly subjects. For this reason, predictive values of spirometry were greater than that of previous results, over-predicting lung age, even in non-smokers. Future research should be planned to reduce the gap between lung age and chronological age in never smokers. ${ }^{24)}$ If a large-scale study similar to Hansen's study ${ }^{24)}$ was conducted for the Korean population, a more powerful model could be developed.

Our study has several strengths. First, this is the first Korean lung age study and it can provide the basis for research about lung age in this population. ${ }^{2,6-8)}$ Second, we compared currently used predictive equations of spirometry with Choi's predictive values of spirometry in the Korean population, and evaluated the association of lung age with smoking using a more suitable equation. Third, a large number of subjects were selected according to strict criteria by standardized measurement and history.

Limitations of this study include the possible inaccuracy of a self-administered questionnaire and recall bias. However, we tried to obtain more accurate information through history taking by physician for past medical history and current symptoms in the same day. The lack of information on exposure to occupational risk factors and secondhand smoking in non-smokers could be another limitation. Large standard deviations in lung age in each group can be problematic when predicting values for an individual as result of wide variability of spirometry results of normal healthy subjects (Table 3 ). Moreover, because this study was conducted retrospectively in a health promotion center at a single tertiary referral hospital, the findings are not generalizable to the broader population, and further randomized controlled trials are required to confirm clinical implications.

In conclusion, we found a significant relationship between lung age and both smoking status and fat mass in healthy Korean males. Further research is needed to fully explore the usefulness of lung age in the Korean population.

\section{CONFLICT OF INTEREST}

No potential conflict of interest relevant to this article was reported.

\section{REFERENCES}

1. Doll R, Peto R, Boreham J, Sutherland I. Mortality in relation to smoking: 50 years' observations on male British doctors. BMJ 2004;328:1519.

2. Bize R, Burnand B, Mueller Y, Cornuz J. Biomedical risk assessment as an aid for smoking cessation. Cochrane Database Syst Rev 2005; (4):CD004705.

3. National Collaborating Centre for Chronic Conditions. Chronic obstructive pulmonary disease. National clinical guideline on management of chronic obstructive pulmonary disease in adults in primary and secondary care. Thorax 2004; 59 Suppl 1:1-232.

4. Soriano JB, Maier WC, Egger P, Visick G, Thakrar B, Sykes J, et al. Recent trends in physician diagnosed COPD in women and men in the UK. Thorax 2000;55:789-94.

5. Morris JF, Temple W. Spirometric "lung age" estimation for motivating smoking cessation. Prev Med 1985;14:655-62.

6. Mitsumune T, Senoh E, Nishikawa H, Adachi M, Kajii E. The effect of obesity and smoking status on lung age in Japanese men. Respirology 2009;14:757-60

7. Newbury W, Newbury J, Briggs N, Crockett A. Exploring the need to update lung age equations. Prim Care Respir J 2010; 19:242-7.

8. Parkes G, Greenhalgh T, Griffin M, Dent R. Effect on smoking quit rate of telling patients their lung age: the Step2quit randomised controlled trial. BMJ 2008;336:598-600. 
9. Parker DR, Goldman RE, Eaton CB. A qualitative study of individuals at risk for or who have chronic obstructive pulmonary disease: what do they understand about their disease? Lung 2008; 186:313-6.

10. Toda R, Hoshino T, Kawayama T, Imaoka H, Sakazaki Y, Tsuda T, et al. Validation of "lung age" measured by spirometry and handy electronic FEV1/FEV6 meter in pulmonary diseases. Intern Med 2009;48:513-21.

11. Choi JK, Paek D, Lee JO. Normal predictive values of spirometry in Korean population. Tuberc Respir Dis 2005; 58:230-42.

12. American Thoracic Society. Lung function testing: selection of reference values and interpretative strategies. Am Rev Respir Dis 1991;144:1202-18.

13. Centers for Disease Control and Prevention (CDC). Cigarette smoking among adults--United States, 1992, and changes in the definition of current cigarette smoking. MMWR Morb Mortal Wkly Rep 1994;43:342-6.

14. Wada T. Lung age in smokers, past smokers anid non secondhand smoke. Rinsho Byori 2009;57:1159-63.

15. Dockery DW, Speizer FE, Ferris BG Jr, Ware JH, Louis TA, Spiro A 3rd. Cumulative and reversible effects of lifetime smoking on simple tests of lung function in adults. Am Rev Respir Dis 1988;137:286-92.

16. Beck GJ, Doyle CA, Schachter EN. Smoking and lung function.
Am Rev Respir Dis 1981;123:149-55.

17. Ashley F, Kannel WB, Sorlie PD, Masson R. Pulmonary function: relation to aging, cigarette habit, and mortality. Ann Intern Med 1975;82:739-45.

18. Kanner RE, Renzetti AD Jr, Klauber MR, Smith CB, Golden CA. Variables associated with changes in spirometry in patients with obstructive lung diseases. Am J Med 1979;67:4450.

19. Chen Y, Rennie D, Cormier YF, Dosman J. Waist circumference is associated with pulmonary function in normal-weight, overweight, and obese subjects. Am J Clin Nutr 2007;85:35-9.

20. Koziel S, Ulijaszek SJ, Szklarska A, Bielicki T. The effects of fatness and fat distribution on respiratory functions. Ann Hum Biol 2007;34:123-31.

21. Collins LC, Hoberty PD, Walker JF, Fletcher EC, Peiris AN. The effect of body fat distribution on pulmonary function tests. Chest 1995; 107:1298-302.

22. Jones RL, Nzekwu MM. The effects of body mass index on lung volumes. Chest 2006;130:827-33.

23. Santana H, Zoico E, Turcato E, Tosoni P, Bissoli L, Olivieri M, et al. Relation between body composition, fat distribution, and lung function in elderly men. Am J Clin Nutr 2001;73:827-31.

24. Hansen J. Measuring the lung age of smokers. Prim Care Respir J 2010;19:286-7. 